\title{
Remote-audit and VR support in precision and mechanical engineering
}

Philipp Greiner, Tania Bogatsch, Norbert Jahn, Laurin Martins, Gerhard Linß, et al.

Philipp Greiner, Tania Bogatsch, Norbert Jahn, Laurin Martins, Gerhard Linß, Gunther Notni, "Remote-audit and VR support in precision and mechanical engineering," Proc. SPIE 11144, Photonics and Education in Measurement Science 2019, 111440C (17 September 2019); doi: 10.1117/12.2533016

SPIE Event: Joint TC1 - TC2 International Symposium on Photonics and Education in Measurement Science 2019, 2019, Jena, Germany 


\title{
Remote-Audit and VR Support in Precision and Mechanical Engineering
}

\author{
Philipp Greiner ${ }^{\mathrm{a}}$, Tania Bogatsch ${ }^{\mathrm{b}}$, Norbert Jahn $^{\mathrm{a}}$, Laurin Martins ${ }^{\mathrm{a}}$, Gerhard Linß ${ }^{\mathrm{a}}$, and \\ Gunther Notni ${ }^{\mathrm{b}}$ \\ ${ }^{a}$ SQB GmbH, Werner-von-Siemens-Str. 9, 98693 Ilmenau, Germany \\ ${ }^{b}$ TU Ilmenau, Fakultät für Maschinenbau, Fachgebiet Qualitätssicherung und Industrielle \\ Bildverarbeitung, Gustav-Kirchhoff-Platz 2, 98693 Ilmenau, Germany
}

\begin{abstract}
The aim of this work is to develop possibilities of an effective audit procedure. Audits are systematic, independent and documented processes for obtaining evidence. This ensures conformity with the requirements. In order to achieve certification according to standards, an external system audit must be carried out by an accredited company. These are very time-consuming and costly because the auditor has to be on site. A concept of how the audit can be carried out without an on-site appointment is developed and evaluated. The possibilities of current technologies - such as VR - are also considered and integrated into the concept. Due to the high-level structure this can be carried out on an integrated audit which combines different management systems.
\end{abstract}

Keywords: System audit, virtual reality, remote-audit, certification, auditor, standards, management systems, external audit

\section{INTRODUCTION}

According to ISO 19011:2018, an audit is a "systematic, independent and documented process for obtaining objective evidence and evaluating it objectively to determine the extent to which the audit criteria are fulfilled". This review is performed by the auditor. He audits the defined area or organization. ${ }^{1}$

The standard ISO 19011:2018 is a guideline for auditing management systems. It provides guidance on auditing management systems. Audit principles are pointed out, creation and control of audit programs are described and instructions for the preparation and execution of audits are given. Requirements for auditors are also described. The current revision is the third edition. ${ }^{1}$

According to ISO 9000:2015, an auditor is a "person who conducts an audit". The auditor's tasks include identifying opportunities for improvement and verifying conformity with relevant standards, laws and regulations ${ }^{2}$ (see figure 1).

Audits can be divided into first party, second party and third party audits. First party audits are internal audits. This is an audit commissioned by the management of the organization. The auditor is usually an employee of the organization. Second party audits are carried out by external providers, for example, supplier audits. They are also external audits. But unlike these, here are the auditors of certification or accreditation bodies who check the legal, official and/or standard requirements. ${ }^{1}$

Further author information:

Philipp Greiner: E-mail: philipp.greiner@quick-image.de, Telephone: +49 15140424443

Website: www.quick-image.de

Photonics and Education in Measurement Science 2019, edited by Maik Rosenberger,

Paul-Gerald Dittrich, Bernhard Zagar, Proc. of SPIE Vol. 11144, 111440C

(C) 2019 SPIE · CCC code: 0277-786X/19/\$21 · doi: 10.1117/12.2533016

Proc. of SPIE Vol. 11144 111440C-1 


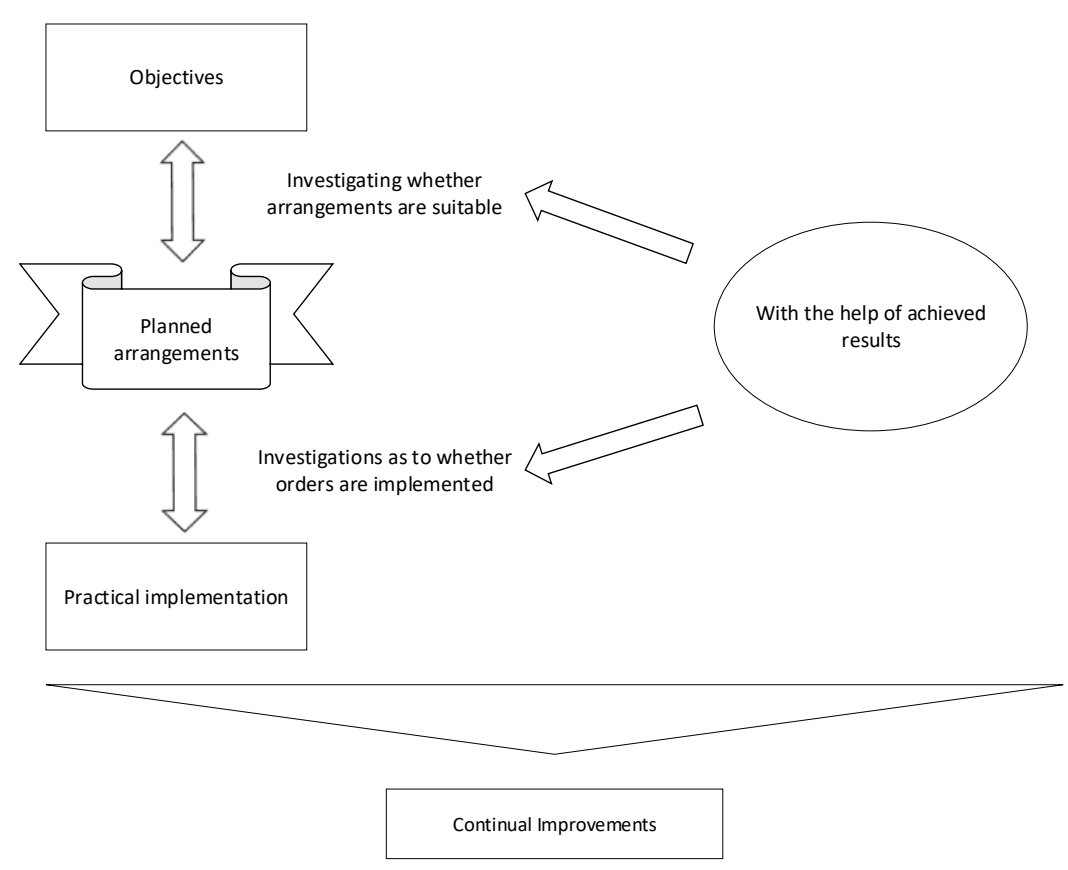

Figure 1. Tasks of the auditor ${ }^{3}$

Furthermore, audits can be classified according to their objectives and focus points. The most important audits are:

- System audit,

- Process audit,

- Procedure audit,

- Product audit,

- Performance audit and

- Compliance audit..$^{3,4}$

The system audit assesses the effectiveness of the quality management system. It is evaluated to what extent the quality-related activities are able to fulfil the requirements (e.g. quality objectives). Here the complete quality management system or a part can be audited. There are both internal and external system audits. Reasons for system audits can be standard requirements for the regular review of the quality management system (e.g. ISO 9001:2015), certification audits or supplier audits. ${ }^{3,4}$

In a process audit, a review of selected processes for possible improvement potentials takes place. In contrast to a system audit, not the entire quality management system is checked, but only individual processes. ${ }^{3,4}$

The procedure audit is the same as the process audit. Instead of processes, however, procedures are audited here.

The product audit checks the conformity of the requirements for products. This refers to customer requirements, specifications, standard requirements, drawings and legal regulations. In addition to checking the conformity with the requirements, other targets are to check the quality and to determine the capability of the testing laboratory. ${ }^{3,4}$ 
The performance audit is becoming more and more important. Like the compliance audit, it is increasingly being used in environmental protection and occupational safety. The main objective is to improve the performance of the company. The key performance indicators of the organization are evaluated and questioned with regard to the degree of achievement and effectiveness. The focus is on the continuous improvement of the output. $^{3}$

The compliance audit checks compliance with legal and official requirements. Among other things, it examines whether the requirements of laws, ordinances, regulations, contracts and guidelines are adhered to. Due to the increasing legal and official requirements this type of audit is becoming more and more common. ${ }^{3}$

When planning and conducting audits, several documented pieces of information must be produced. Before an audit can be performed, an audit program must be created. This involves planning when which audit is to be performed for a certain period of time (e.g. for the current year). This schedule helps to prepare the individual audits better.

To prepare an audit, the audit plan must be created for each audit. In addition to determining the concrete date of the audit, the audit plan also contains the auditor(s), the audited area and the relevant standards. A rough timetable of when which topics are to be dealt with is also drawn up.

After the audit has been carried out, the audit report must be prepared. The audit report includes the evaluation of the audit. In addition to the organizational information (date, auditor(s), audited area, etc.), this report must describe the audit procedure. Particular attention must be paid to the requirements of the audited standards. Suggestions for improvement and hints are described in the audit report. Any deviations from requirements found must be described in the audit report. Deviations, which can lead to the failure of the management system, lead to the unsuccessful conclusion of the audit.

\section{THE PROCEDURE OF AN AUDIT}

For this elaboration the (internal and external) system audit is considered. This includes certification audits by accredited certification organizations. The following figure shows the separate steps on the way to certification.

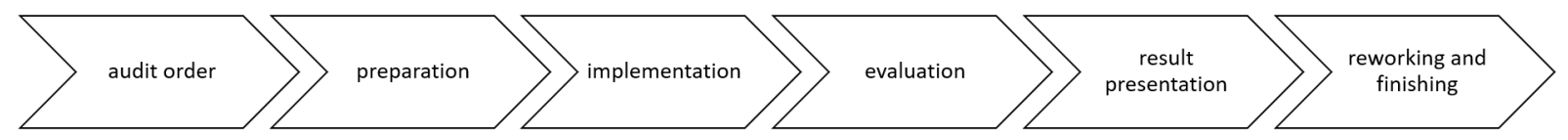

Figure 2. The way to certification

Before the actual audit can be carried out, preparations are necessary. In addition to preparing the required documentation (audit program, audit plan and audit report), the requirements of the standard to be certified must also be fulfilled. This is usually fulfilled by the company (e.g. authorized representative).

The basic procedure of certification audits (external system audits) is always similar. After the agreement between the auditor and the company to be audited on the modalities (organizational) has been made, important documents are sent from the company to the auditor a certain time before the audit. Depending on the certification, these documents differ. In a certification according to ISO 9001:2015, the auditor usually requests documents about the scope of quality management, internal audit reports, the process landscape (process descriptions and procedures), quality objectives and policies as well as the management evaluation. The auditor examines these documents and can thus gain an overview of the company and check whether the documentation meets the requirements of the standard(s). Inconsistencies in the documentation can be discussed with the companies so that they can be resolved before the auditor visits.

The auditor visits the company for an on-site appointment on the date set by both parties. The duration of the audit depends on many factors such as the size of the company and the standards to be certified. The International Accreditation Forum specifies how long the audit should last, depending on the number of employees in the organisation. One audit day corresponds to 8 hours. ${ }^{5}$ 
Table 1. Relationship between effective number of personnel and audit duration ${ }^{5}$

\begin{tabular}{|c|c|c|c|}
\hline $\begin{array}{c}\text { Effective Number } \\
\text { of Personnel }\end{array}$ & $\begin{array}{c}\text { Audit Duration Stage 1 } \\
\text { and Stage 2 (days) }\end{array}$ & $\begin{array}{c}\text { Effective Number } \\
\text { of Personnel }\end{array}$ & $\begin{array}{c}\text { Audit Duration Stage 1 } \\
\text { and Stage 2 (days) }\end{array}$ \\
\hline $1-5$ & 1.5 & $626-875$ & 12 \\
\hline $6-10$ & 2 & $876-1175$ & 13 \\
\hline $11-15$ & 2.5 & $1176-1550$ & 14 \\
\hline $16-25$ & 3 & $1551-2025$ & 15 \\
\hline $26-45$ & 4 & $2026-2675$ & 16 \\
\hline $46-65$ & 5 & $2676-3450$ & 18 \\
\hline $66-85$ & 6 & $3451-4350$ & 19 \\
\hline $86-125$ & 7 & $4351-5450$ & 20 \\
\hline $126-175$ & 8 & $5451-6800$ & 22 \\
\hline $176-275$ & 9 & $6801-8500$ & \\
\hline $276-425$ & 10 & $8501-10700$ & Follow progression above \\
\hline $426-625$ & 11 & $>10700$ & \\
\hline
\end{tabular}

According to IAF, ${ }^{5}$ audit activities are usually one of them:

- conducting the opening meeting,

- reviewing documents during the performance of audits,

- communication during the audit,

- role allocation and allocation of responsibilities among supervisors and observers,

- collecting and verifying information,

- preparation of audit findings,

- preparation of audit conclusions and

- conducting the final discussion.

After the audit has been carried out, the post-processing is due. The auditor prepares the findings he has ascertained during the audit. Any indications and deviations found - which could not be rectified during the audit - must be reworked by the company. In the case of non-serious indications and deviations, the auditor usually checks the corrections by submitting subsequent documents. A new on-site visit is not necessary. For larger, critical deviations, a post-audit is usually necessary. The auditor checks the elimination of the deviations during a new on-site visit. When all relevant deviations have been rectified, the auditor prepares his audit report, which describes how the company meets the requirements.

\section{Procedure with the help of Remote and VR}

As a rule, the preparation and follow-up of audits today already takes place without an on-site appointment by the auditor. The required documentation is sent by email. Agreements between the two parties can be established by means of video/telephone conferences.

The execution of the audit is more problematic. By default, the auditor is present on site. While the review of the documentation and discussions with the management and the representatives can be carried out via a 
video conference without any major compromises, the tour of the plant represents a special challenge. Since the auditor is not on the site, he must be present virtually in order to inspect the factory halls and the working environment. One possibility is to implement this using a VR-System (Virtual Reality). This system consists of a camera with a microphone, which delivers video and audio information, and VR glasses. One person in the company must carry the camera. The most comfortable way is to use a front camera. The camera is attached to the head by means of a bracket. The camera records what the wearer sees. With this construction, the person walks through the factory hall. The auditor wears the VR glasses. With this he sees a 3-dimensional virtual environment of the factory hall. This system offers the following advantage over a 2-dimensional video recording:

- The auditor can look around freely. The system offers a 360 degree viewing angle.

- Through the VR glasses, the auditor sees the factory hall 3-dimensionally. This offers more information (depths etc.) than a 2-dimensional recording.

- The virtual environment minimizes distraction from the real environment, allowing the auditor to fully focus on the important information.

\section{TECHNOLOGIES}

\subsection{Video/Telephone Conference}

Video and telephone conferences have long been used in the business sector. This option facilitates communication with several participants, even over long distances. One of the most widely used video conferencing programs in business is Skype from Microsoft. A suitable telephone is required for telephone conferences and a webcam, computer, beamer or monitor and an internet connection at an appropriate speed are required for video conferences.

\subsection{Remote}

Remote means having access to something even though the person is not nearby. For virtual audits, remote access is suitable to the computer in the company on which the documents relevant for the audit are stored. This makes it possible for the auditor to search the documents remotely. The advantage is that the company does not have to send all documents to the auditor. In addition to the problem of sending the large data package to the auditor, another advantage is that the company retains control over the data.

\subsection{VR-System}

Development in the field of VR (virtual reality) has been going on for several decades. The first VR headmounted display (HMD) was developed by computer specialist Ivan Sutherland in 1968. In the next decades this topic came up again and again and there were new developments. However, this technology could not really assert itself.

A driving force in the development was the video game industry. This is also the driving force behind the increasing investments in this area since the beginning of the 2010s. Palmer Luckey created the first prototype of the Oculus Rift (VR glasses) in 2010. With its VR glasses, Palmer Luckey wants to offer a technically mature system at an affordable price even for the mass market. With the help of a kickstarter campaign* he collected several million dollars with his idea. In 2014, Facebook Inc. bought his company for $\$ 2$ billion. A first development version of the glasses has been available since 2013. The version for the end user was released in 2016. Special features compared to earlier VR glasses are a 90-degree field of view, the higher resolution of the display and the weight, which allows a more comfortable wearing. Figure 3 shows a current version of the Oculus Rift VR-Headset.

By the end of 2010 a lot of companies are working on their own VR-Headsets. Among them are some industry giants like Sony (Playstation VR) and HTC (HTC Vive). Many other companies are working on software for these systems. The pressure to innovate is very high due to the many competitors, which means that the systems are constantly being improved. The display resolution increases and the ppi ${ }^{\dagger}$, resulting in sharper and more detailed images. The weight of the systems is reduced, which increases wearing comfort. ${ }^{6}$

\footnotetext{
*Kickstarter is a crowdfunding platform. People and institutions can give money to finance projects.

${ }^{\dagger}$ ppi stands for part per inch, this is a parameter for the pixels per screen area.
} 


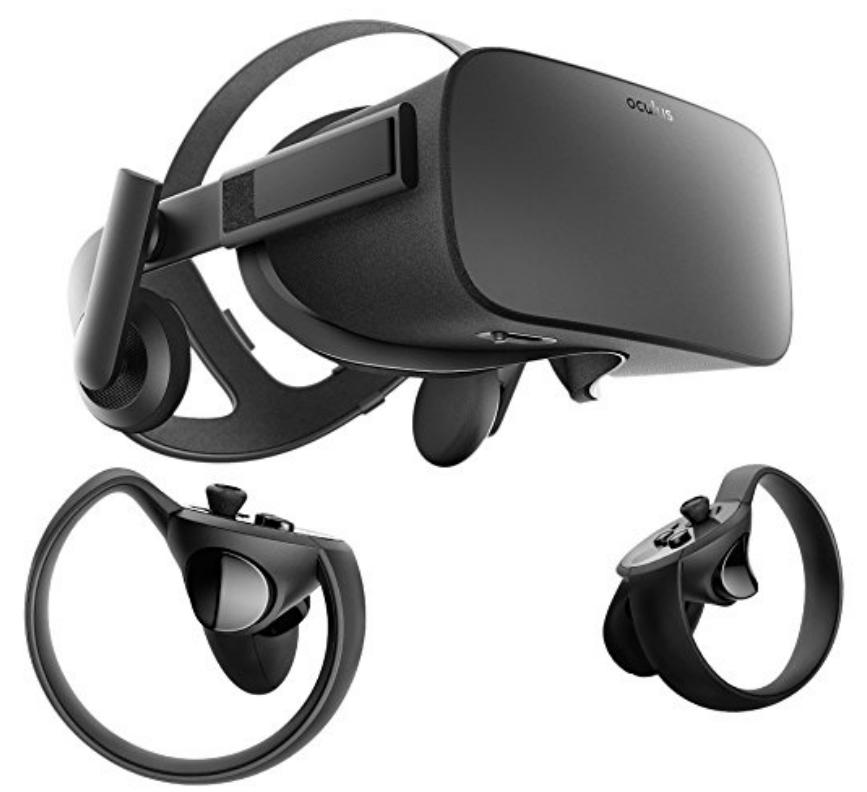

Figure 3. Oculus Rift VR-Headset ${ }^{7}$

\section{BENEFITS OF VIRTUAL AUDITS}

The biggest benefits of an virtual audit compared to a conventional audit are the time and cost savings. The time savings are mainly due to the fact that the auditors are not present on site. This eliminates the need to travel to and from the site. For audits lasting several days, there is no need for hotel accommodation. The cost savings result from these time savings. Travel costs and costs for overnight stays, if applicable, are eliminated. Depending on the size of the company, several days can be spent together (compare table 1).

Another advantage is the flexible time management. While conventional audits are carried out on one or more days, the time management of virtual audits can be made more flexible. The review of the documentation and discussions with the management and the representatives can be carried out on a different day than the plant tour. This can also be divided into several days. The advantage for the company lies in the fact that the audit representatives do not have to reserve one or more complete days for this.

\section{CONCLUSION AND FUTURE WORK}

This paper presented an insight into remote audits. As standards become more stringent, audits become more extensive and time-consuming. Remote audits with VR support can help to make audits more efficient. The technologies for this are constantly being further developed and are being used more and more in the industrial sector. Since VR-Systems are becoming more and more popular in the computer and video game industry and are also used in other areas such as education/training (e.g. practice of pilots) and factory planning (virtual factory view before completion), there will be further developments in this area in the coming years.

\section{REFERENCES}

[1] Standard, [ISO 19011:2018: Guidelines for auditing management systems], International Organization for Standardization (November 2018).

[2] Standard, [ISO 9000:2015: Quality management systems - Fundamentals and vocabulary], International Organization for Standardization (November 2015).

[3] Kamiske, G. F., [Handbuch QM-Methoden: Die richtige Methode auswählen und erfolgreich umsetzen], Carl Hansa Verlag, Munich (2015 (third edition)).

[4] Linß, G., [Qualitätsmanagement für Ingenieure], Carl Hansa Verlag, Munich (2018 (fourth edition)). 
[5] Forum, I. A., "IAF Mandatory Documentfor Duration of QMS and EMS Audits." 4 March 2013 https: //www.iaf.nu/upFiles/IAFMD52013QMSEMSAuditDurationPub.pdf. (Accessed: 18 April 2019).

[6] Dormehl, L., "8 virtual reality milestones that took it from sci-fi to your living room." 13 November 2017 https://www.digitaltrends.com/cool-tech/history-of-virtual-reality/. (Accessed: 18 April 2019).

[7] amazon.com, "Image of the Oculus Rift VR-Headset." https://images-na.ssl-images-amazon.com/ images/I/61ueGFutGgL._SL1000_.jpg. (Accessed: 18 April 2019). 